DOI: http://dx.doi.org/10.22198/rys.2018.72.a838

Artículos

\title{
Democracia y autonomía en organizaciones sociales de base femenina del sur de Sonora: el caso Cobanaras Federación
}

\author{
Democracy and autonomy in female-based social \\ organizations in southern Sonora: \\ the Cobanaras Federation case
}

\author{
Nehiby Alcántara Nieves* \\ María del Carmen Hernández Moreno**
}

Resumen: en este artículo se describen los vínculos que establece una organización de base social entre sus miembros y con los actores externos, por medio de una tipología que conceptualiza tales vínculos en clientelar-corporativo, neoliberal y democrático-participativo, cada uno relacionado con prácticas internas específicas de autonomía y democracia. La hipótesis del trabajo es que la tensión entre estos vínculos influye en la estructura y en los procesos de una organización social condicionando su continuidad y consolidación. Para probarla se efectuó un estudio cualitativo, fincado en la sistematización de la genealogía, la morfología y la dinámica de Cobanaras Federación, una organización de base fe-

\footnotetext{
* Doctora en ciencias por el Centro de Investigación en Alimentación y Desarrollo, A. C. Carretera a La Victoria, km 0.6 s/n, ejido La Victoria, C. P. 83304 . Hermosillo Sonora, México. Teléfono: (662) 289 2400. Correo electrónico: nehiby.alcantara@gmail.com

** Autora para correspondencia. Investigadora titular de la Coordinación de Desarrollo Regional del Centro de Investigación en Alimentación y Desarrollo, A. C. Teléfono: (662) 289 2400, extensión 321. Correo electrónico: mar@ciad.mx
} 
menina del sur de Sonora. Entre los resultados destaca que, como estrategia de sobrevivencia, las interacciones de dicha agrupación se concretan en una combinación tensa entre los tres tipos de vínculos en disputa, con mayor énfasis en los neoliberales, como presión externa, sobre los democrático-participativos, como expresión de resistencia interna.

Palabras clave: autonomía; democracia; organizaciones sociales; mujeres; neoliberalismo; Sonora.

Abstract: this article describes the links established by a socially based organization among its members and with external actors by means of a typology that conceptualizes such links as clientelist-corporate, neoliberal and democraticparticipative, each one related to specific internal practices of autonomy and democracy. The working hypothesis is that tension among these links has an influence on a social organization's structure and processes, conditioning their continuity and consolidation. In order to test it, a qualitative study was conducted based on the systematization of the genealogy, morphology and dynamics of Cobanaras Federation, a female-based organization in southern Sonora. Among the results, it should be highlighted that, as a survival strategy, interactions of this group are materialized in a tense combination among the three types of disputing links, with a greater emphasis on neoliberal ones, as an external pressure, than on democratic-participative ones, as an expression of internal resistance.

Keywords: autonomy; democracy; social organizations, women; neoliberalism; Sonora. 


\section{Introducción}

Las últimas décadas del siglo XX estuvieron marcadas por la redefinición global de los roles y las relaciones entre el Estado, la sociedad y los agentes económicos, como parte de la implementación del proyecto neoliberal (Ortiz 2014). En este proceso, la reducción del Estado abrió el espacio público, hasta entonces dominado por organizaciones gremiales, inmersas en relaciones clientelares-corporativas y regidas por el autoritarismo estatal, a una sociedad civil renovada, compuesta por agrupaciones independientes y nuevos movimientos sociales, culturales y globales, que revalorizaron la democracia en la vida cotidiana (Calderón 2011, 76; Isin y Turner 2002, 1; Beck 2002, 115; 1997, 27).

Como representantes de esta corriente, en América Latina destacan los movimientos feministas; de derechos humanos y ética en la política; las orientaciones democráticas y participativas del obrerismo; el comunitarismo urbano y rural; los de jóvenes; los étnicos y los religiosos (Calderón 2012, 159). Muchos de ellos se han trasformado en organizaciones de la sociedad civil, formales e institucionalizadas, y en otras no gubernamentales (ONG), encargadas de materializar sus demandas generales en proyectos concretos.

Entre las novedades que caracterizan a los actores noveles están su integración y actuación a través de estructuras menos jerarquizadas y más flexibles, en comparación con las formas tradicionales de organización gremial y clasista (Durand 2002, 111), con una visión renovada de la política, en cuyo caso la escala geográfica se globaliza y las acciones se canalizan desde sitios nuevos de contestación (Isin 2009, 368; Calderón 2011, 77). Así, desde esta faz de la sociedad civil se impele un proyecto democrático-participativo, que busca diluir el carácter excluyente y elitista de la democracia representativa, como sistema privilegiado de relaciones entre el Estado y la sociedad (Dagnino et al. 2006, 51), además de contrarrestar los vestigios de las aún arraigadas formas clientelares-corporativas.

En esta dinámica, las mujeres parecen estar a la vanguardia en la implementación de políticas neoliberales, sobre todo quienes, perteneciendo a sectores populares, salieron a la escena pública para ha- 
cerles frente a sus impactos sociales (Echaverría y Bard 2013, 90). Ellas pasaron de organizaciones mixtas (hombres y mujeres) a conformar otras de base femenina, y a construir proyectos propios. Sin embargo, frente a este potencial, las organizaciones de mujeres aún son moneda de cambio en la arena de las contiendas electorales y de la negociación de políticas públicas focalizadas.

Este proceso se desarrolla en torno a intercambios materiales y simbólicos que fluyen a través de vínculos, entendidos como las interacciones entre los actores sociales, políticos y económicos que buscan influir unos en otros para su reproducción. Garretón (2002) y Dagnino et al. (2006) coinciden en identificar la coexistencia de tres proyectos o tendencias políticas que rigen tales vínculos: autoritario o clientelar-corporativo; neoliberal y democrático-participativo, en cuya confrontación media la disputa por la democratización y autonomía del espacio público, así como de la estructura y procesos internos de la propia organización.

Con base en este marco conceptual, el objetivo del artículo es caracterizar los vínculos que una organización social (OS) de base femenina establece con actores externos y cómo, a raíz de estas interacciones, se modifican sus procesos de autonomía y democracia. Tras este planteamiento subyace la hipótesis de que la tensión entre los vínculos internos y externos de una OS influye en su estructura y procesos condicionando su continuidad y consolidación. Como ruta crítica para probarla, se sistematizó la información de la organización con el modelo propuesto por Montes de Oca $(2014,290)$, que consta de tres niveles analíticos: la genealogía, la morfología y la dinámica, que permiten representar de manera integral a los actores internos (membresía) y externos (gubernamentales, sociales y económicos), así como a los vínculos y dinámicas desarrollados en su interacción.

Como estudio de caso se tomó a Cobanaras Federación Estatal de Sociedades de Solidaridad Social (Cobanaras Federación), integrada por mujeres del sur de Sonora y constituida legalmente en 1994, cuyos orígenes se remontan a la toma de tierras de 1976 en esa región, y a las acciones de un grupo de mujeres feministas que se adhirieron a esta lucha. En la actualidad se le reconoce como una OS de base femenina autónoma, promotora del ahorro y de los derechos de las mujeres. 
Los resultados de la investigación están divididos en cuatro apartados; en el primero se expone el contexto de la transición de un Estado de bienestar al neoliberalismo, su repercusión en la emergencia y protagonismo de nuevos actores sociales y en sus formas de vinculación; así como la tipología utilizada para analizar las interacciones con los actores internos y externos de Cobanaras Federación. En el segundo se describe la estrategia metodológica, fincada en la sistematización de la trayectoria de la organización, a partir del análisis de contenido de entrevistas y de observación directa y participante. Después se presenta la caracterización y revisión de los vínculos de esta OS en el contexto de su genealogía, morfología y dinámica, y cómo influyen en sus procesos democráticos y de autonomía. Con base en este análisis se concluye que la trayectoria de Cobanaras Federación trascurre en tensión permanente entre las tres formas de vínculos aludidas; ello se interpreta como estrategia de sobrevivencia en la que el punto central es la disputa entre los vínculos neoliberales, como la presión externa, principalmente de instituciones financiadoras y gubernamentales, sobre los de tipo democrático-participativo, impulsados desde la membresía, como expresión de resistencia interna.

\section{Neoliberalismo, autonomía y democracia en organizaciones sociales de base femenina}

La tríada básica del neoliberalismo (desregulación, liberalización y privatización) redujo la presencia del Estado en la vida cotidiana, y con ello trajo el ideal del ciudadano autosuficiente y responsable del desarrollo de su propio bienestar (Harvey 2007, 6). En todo caso, el fin último de la implementación de las políticas neoliberales es "transferir a la sociedad en general, y a los beneficiarios de los programas en particular, responsabilidades, control y, eventualmente, poder efectivo" (Banco Interamericano de Desarrollo-Programa de Naciones Unidas para el Desarrollo, BID-PNUD 1993, 35).

Así, el esquema neoliberal configuró la noción de un ciudadano individualizado y autosuficiente, cuyo éxito o fracaso en la obtención de su bienestar se atribuye directamente a decisiones personales, y no 
a algún tipo de cualidad sistémica (Beck 2002; Harvey 2007). Esto contribuyó a la precarización en las condiciones de vida de amplios sectores de la población que, incapaces de acceder a servicios y empleo, a través de la lógica del mercado, se convirtieron en blanco de políticas focalizadas; lo que generó en ellos la "identidad del asistido y la asistida permanente dependientes del favor de gobiernos y organismos no gubernamentales" (Coraggio 2008, 83).

Dicho proceso implicó la tendencia hacia una individualización asocial, a la que Castells se refiere como "individualismo negativo", que repliega a lo privado a quienes carecen de eficiencia personal y lazos sociales sobre los cuales apoyarse (Balibar 2012, 78-79). Beck $(2002,14)$ da cuenta de otra senda de la individualización que, lejos de poner en riesgo la integración y aislamiento del individuo, suscita la creatividad para la renovación de la sociedad en condiciones de cambio radical. Lechner $(2004,40)$ abona a la discusión al argumentar que la individualización permite incrementar las capacidades de las personas para participar en la vida social, como sujeto personal apto para configurar una multiplicidad de actores, individuales y colectivos, imbricados en una variedad de sistemas de creencias y valores (Wieviorka 2011; Touraine 2006).

Así, cuando el sujeto se separa de las clases y fuerzas sociales presentes en la sociedad industrial, el movimiento nuclear, regido por la lucha de clase y el Estado como locus de poder, pierde centralidad en el espacio público y emerge la acción colectiva en forma de movimientos sociales (Calderón 2011, 76; Wieviorka 2011, 98) y culturales nuevos (Touraine 2006, 273) entre los que destacan los de mujeres, estudiantes, indígenas y los globales, como el anticapitalista, el antiimperialista y el globalifóbico (Wieviorka 2011, 107).

En medio de esta transición, a dichos movimientos contemporáneos se les reconoce como una forma de participación de las y los ciudadanos en la vida pública (Cohen y Arato 2000, 38), y como elemento primigenio, a la vez que trasformador, de la sociedad civil organizada (Olvera 2000, 14). Es decir, en esta última se pueden encontrar dos expresiones colectivas: los movimientos sociales y las formas organizativas más estructuradas e institucionalizadas, que representan el aspecto formal de los primeros, y cuya finalidad es la 
materialización de principios más generales (Olvera 2000, 8). En este sentido, cabe la aclaración de Diamond $(1997,3)$ respecto a que los movimientos y las OS sólo pueden considerarse parte de la sociedad civil cuando buscan el bien colectivo, y no la obtención del poder estatal para sí mismos.

Entonces, la sociedad civil representa las acciones colectivas y promueve la formación de vínculos en favor de la autonomía de las y los actores sociales, en contra del funcionamiento de la lógica del mercado y la voluntad política de dominación, y se desfigura cuando las demandas sociales se subordinan a un programa político (Touraine 2001, 107-108). Al respecto, el autor refiere a la fragmentación y a la debilidad ideológica, características de los nuevos movimientos sociales, culturales y globales, como elementos que confieren mayor independencia y capacidad de vincular lo social con lo político. Y prosigue en su discusión, al comparar el rápido agotamiento de los movimientos prepolíticos o parapolíticos de la década de 1970, con el de mujeres que, sin convertirse en fuerza política, logró penetrar las relaciones familiares así como las concepciones del derecho y la educación nutriendo la formación de organizaciones capaces de materializar sus demandas. Al respecto, Bartra $(1992,99)$ indica que la acción colectiva produce en las mujeres una transición del plano individual al comunitario, proceso que se presentó como fuerza social y, en último término, fuerza política. Así, la participación y la organización femeninas generan expresiones evidentes de práctica democrática (Bartra 1992, 100), que favorecen el empoderamiento y cuestionan las relaciones tradicionales de poder (Martínez et al. 2005, 301).

Es importante mencionar que las luchas de las mujeres, por lo general se gestaron en colectivos mixtos, es decir, formados primordialmente por hombres que le dieron cabida a la participación femenina. Pero, aun cuando su involucramiento en éstos contribuyó al logro de metas comunes, en tanto colectivo mixto, se tiene evidencia de que una vez alcanzadas, las mujeres perdieron visibilidad y sus demandas particulares no se tomaron en cuenta (Martínez et al. 2005, 281-286; Lara 1994, 87).

En este esquema, las relaciones de democracia y autonomía consideraban poco a las mujeres, quienes se mantenían al margen de 
la toma de decisiones y del manejo de recursos. No obstante, su incursión les permitió tener un primer acercamiento a la política y generar un aprendizaje que posibilitó el emprendimiento de sus organizaciones, con reivindicaciones, expectativas e intereses propios (Martínez et al. 2005, 281-286; Lara 1994, 87; Canabal 2003, 215).

De acuerdo con Touraine $(2007,194)$, este proceso se relaciona con la formación del sujeto, detonado por la negación de la mujer a su subjetividad. "El sujeto se construye imponiendo a la sociedad límites y principios de organización conforme a su deseo de libertad y voluntad de crear formas de vida social favorables a la afirmación de sí mismo y de reconocimiento del otro como sujeto" (Touraine $2000,90)$. Estas características se ven reflejadas en la formación de redes de apoyo entre grupos de mujeres de distintas clases sociales y latitudes (Lara 1994, 87).

Según un estudio del BID, las organizaciones de base, que incluyen a las de mujeres, han compensado el vacío de liderazgo político que dejaron los partidos (Buvinic y Roza 2004, 8) y, en general, el de las formas tradicionales de organización. Sin embargo, es común que operen en su comunidad a partir de recursos canalizados desde el exterior y aplicados a necesidades inmediatas. En este sentido, Reuben (1992) citado en Somuano $(2011,242)$ advierte la conformación de modelos ficticios de producción y organización popular; contexto que se vislumbra con pocas probabilidades de contribuir a la ruptura de relaciones corporativistas y, en el largo plazo, a empoderar a grupos subordinados.

En un estudio sobre liderazgo en agrupaciones de mujeres en Perú, Jenkins $(2011,303)$ reportó una tendencia a la despolitización y crecimiento de conductas individualistas en las participantes, en principio relacionada con la penetración de las políticas neoliberales y al final con las acciones represivas y violentas de Sendero Luminoso en contra de sus integrantes. Según la autora, la implementación de políticas neoliberales significó la transición del activismo del cambio social, a la procuración de exigencias gerenciales nuevas, como la rendición de cuentas, la eficiencia, la buena gestión financiera y los resultados cuantificables de política pública. 
En sentido estricto, estas medidas abonan a la democracia al trasparentar los recursos, sin requerir la participación de todas las integrantes $y$, en menor medida, garantiza que el financiamiento otorgado por instituciones públicas y privadas, nacionales e internacionales no condicione los procesos internos de las OS receptoras. Jenkins (2011) encontró que en el ámbito interno, en dicha participación pueden influir las relaciones jerárquicas y autocráticas entre las bases y las dirigentes quienes, de acuerdo con lo reportado, usaron su poder e influencia sobre las integrantes concediendo favores y supervisando la distribución de los bienes entre quienes consideraban sus aliadas.

En este derrotero, cabe la posibilidad de que ciertas organizaciones que luchan por la inclusión, la igualdad y el reconocimiento social ante el sistema político y económico se radicalicen de tal manera que, más que producir prácticas nuevas basadas en la democracia, reproduzcan modelos corporativos y autoritarios internos. La constante en estas interacciones es el intercambio material y simbólico, a través del cual las y los participantes buscan influirse entre sí dando lugar a la creación o réplica de modelos de vinculación entre actores (Olvera $2000,11)$, tanto en su interior como hacia el exterior.

De acuerdo con Sánchez $(2008,209)$, los vínculos son la "unidad básica de configuración de la sociedad”, y tienen un papel primordial en su organización al imbricarse en economía y política, a través de un conjunto de reglas y pautas de comportamiento. También, como forma de regulación social, se imponen reglas desde arriba y se negocian desde abajo. Asimismo, en la relación Estado-sociedad, en el caso colombiano estudiado por el autor, se evidencia que hay vínculos fincados en prácticas clientelares y paternalistas, a la par que se instaura la lógica de mercado.

Sobre esta línea de argumentación, Dagnino et al. (2006, 27, 35 y 40) enfatizan la heterogeneidad de la sociedad civil y del Estado en países latinoamericanos; plantean que la complejidad en las posibilidades de colaboración y confrontación, es decir la forma en la que se vinculan dichos actores, se desarrolla en torno a tres proyectos políticos: el autoritario, el neoliberal y el democrático-participativo. Garretón (2006) también alude a esta diversidad, y coincide con Dagnino et al. $(2006,27,35,40)$ en lo que considera tres tendencias, en ocasiones sobrepuestas, que buscan sustituir el espacio que dejó la 


\section{Figura 1. Caracterización de los vínculos internos y externos de una OS}

\begin{tabular}{|c|c|c|}
\hline \multirow{2}{*}{$\begin{array}{l}\text { Tipo de } \\
\text { vínculo }\end{array}$} & \multicolumn{2}{|c|}{ Características según el plano en el que se concreten las interacciones } \\
\hline & Membresía-actores externos & Membresía \\
\hline \multirow[b]{3}{*}{$\begin{array}{l}\text { Clientelar- } \\
\text { corporativo }\end{array}$} & $\begin{array}{c}\text { Verticalidad de las relaciones } \\
\text { entre la sociedad civil } \\
\text { y el Estado }\end{array}$ & $\begin{array}{l}\text { Estructura interna rígida y vertical, } \\
\text { basada en la representación } \\
\text { de intereses agregados }\end{array}$ \\
\hline & Represión y cooptación & $\begin{array}{l}\text { Toma de decisiones a través } \\
\text { de negociaciones de una elite }\end{array}$ \\
\hline & $\begin{array}{l}\text { Sólo se reconocen las } \\
\text { organizaciones vinculadas } \\
\text { al Estado }\end{array}$ & $\begin{array}{c}\text { La movilidad en la estructura interna, } \\
\text { la trasmisión de conocimientos y } \\
\text { flujos de información se logra a través } \\
\text { del acatamiento de las decisiones } \\
\text { establecidas, relacionadas con la lealtad } \\
\text { al líder, o a una elite, que ejerce el poder } \\
\text { interior y distribuye recompensas (Luna } \\
\text { y Tirado 2005) }\end{array}$ \\
\hline \multirow{4}{*}{ Neoliberal } & \multirow{2}{*}{$\begin{array}{l}\text { Relación Estado-sociedad } \\
\text { civil recomendatoria, } \\
\text { no vinculante }\end{array}$} & \begin{tabular}{|c|} 
Estructura horizontal \\
\end{tabular} \\
\hline & & $\begin{array}{l}\text { Jerarquización sobre normas } \\
\text { preestablecidas desde el exterior }\end{array}$ \\
\hline & $\begin{array}{l}\text { Toma de decisiones } \\
\text { descentralizadas }\end{array}$ & $\begin{array}{l}\text { La toma de decisiones responde a una } \\
\text { serie de procedimientos previstos, } \\
\text { donde al final la elección de los cursos } \\
\text { de acción se fundamenta legalmente }\end{array}$ \\
\hline & $\begin{array}{l}\text { Visión selectiva de la } \\
\text { sociedad civil, de acuerdo } \\
\text { con sus capacidades } \\
\text { en la aplicación de } \\
\text { demandas específicas }\end{array}$ & $\begin{array}{l}\text { La movilidad en la estructura se basa } \\
\text { en el cumplimiento y la capacidad } \\
\text { de hacer que se acaten las normas } \\
\text { establecidas (Prats 2005; } \\
\text { Luna y Tirado 2005) }\end{array}$ \\
\hline \multirow{3}{*}{$\begin{array}{l}\text { Democrático- } \\
\text { participativo }\end{array}$} & $\begin{array}{c}\text { Relación recomendatoria } \\
\text { y vinculante } \\
\text { Estado-sociedad civil } \\
\end{array}$ & Estructura flexible y horizontal \\
\hline & $\begin{array}{l}\text { Apertura al debate } \\
\text { para la toma de decisiones }\end{array}$ & \begin{tabular}{|c|} 
La toma de decisiones se realiza \\
a través de un debate informado en el \\
que se confrontan distintos argumentos
\end{tabular} \\
\hline & $\begin{array}{l}\text { Se concibe heterogénea } \\
\text { y reconoce su importancia } \\
\text { en el debate de intereses } \\
\text { divergentes }\end{array}$ & $\begin{array}{l}\text { La movilidad en la estructura y el } \\
\text { flujo de información están en función } \\
\text { de la capacidad y apertura de cada } \\
\text { miembro, para asimilar y trasmitir los } \\
\text { conocimientos (Luna y Tirado 2005; } \\
\text { Barkin y Lumus 2014; Esteva 2014) }\end{array}$ \\
\hline
\end{tabular}

Fuente: elaboración propia, con base en Luna y Tirado (2005); Prats (2005); Barkin y Lumus (2014); Esteva (2014). 
disolución de la matriz sociopolítica nacional-popular o clientelarcorporativa. La primera es la neoliberal; la segunda es una reacción a la anterior, que emerge desde la sociedad civil vinculada a principios comunitarios e identitarios, y la tercera refleja una visión más institucionalizada, a través del reforzamiento del papel del Estado y de la democracia representativa.

Debido a la incapacidad de las tres tendencias para configurar una matriz sociopolítica nueva, diferente a la nacional-popular, emergen vacíos de los que pueden resurgir relaciones clientelares, corporativistas o partidistas, que si bien carecen de la convocatoria de los bloques ideológicos de antaño, poseen un gran potencial fragmentario muchas veces vinculados "a elementos anómicos, apáticos o atomizadores [...]” (Garretón 2002, 14).

Con base en lo expuesto hasta aquí, en relación con la influencia de los vínculos de las organizaciones sociales sobre sus prácticas de autonomía y democracia y asumiendo, como afirman las y los autores citados, la coexistencia de formas superpuestas de relacionarse, se definió una tipología de vínculos -clientelar-corporativa, neoliberal y democrática-participativa-, para caracterizar las interacciones que las OS establecen con el Estado, con actores políticos y económicos y entre sus miembros. Cada tipología está fincada en concepciones específicas sobre el papel que debe asumir la sociedad civil frente al Estado y la institucionalización de prácticas de democracia y autonomía o ausencia de ellas, que permean en las OS. Las interacciones implícitas en los vínculos posibilitan la reproducción de las organizaciones en dos planos: el interno (entre la membresía) y el externo (los integrantes con actores ajenos) (véase Figura 1).

\section{Estrategia metodológica}

En la introducción se planteó el objetivo del estudio: caracterizar los vínculos generados por una agrupación de base femenina, como marco explicativo de sus prácticas de autonomía y democracia. En este planteamiento, las OS se conciben como espacios articulados en torno a una estructura y a procesos internos que determinan la posición y función de sus miembros, dentro de las cuales se generan vínculos, 
es decir, interacciones -al interior y al exterior- impulsadas por intereses, creencias y representaciones, a veces antagónicos (Somuano 2011; Jenkins 2011). Estos vínculos también aluden a una relación entre actores que buscan influirse mutuamente, a través del intercambio de recursos dentro y fuera de la OS (Sánchez 2008; Levitsky y Wolfson 2004; Somuano 2011).

La particularidad es que tales vínculos están ligados a una matriz sociopolítica específica, que determina la orientación de las interacciones prevalecientes dentro y fuera de las OS. En la actualidad, ante la ausencia de una matriz sociopolítica dominante, como lo fue en el pasado la nacional-popular, la cotidianeidad de las OS trascurre en contextos que promueven vínculos fincados en racionalidades de mercado; de resistencia, orientadas a la instauración de estructuras democrático-participativas; o de recuperación de la lógica corporativista; esta complejidad obligó a establecer la tipología de vínculos descrita, y aquí se sostiene la hipótesis de que ésta influye en la estructura y procesos internos de las OS provocando una tensión permanente entre sus vínculos, y que este entramado condiciona su continuidad y consolidación.

Para caracterizar los vínculos y su dinámica e influencia en la trayectoria de la OS se propuso, con base en Montes de Oca (2014), una herramienta para la sistematización consistente en tres niveles de análisis. El primero es la genealogía, que permitió identificar las condiciones fundacionales de la organización e indagar sobre la configuración de sus vínculos, cómo evolucionaron, qué prácticas de participación integraron, cuáles se descartaron y cómo este conjunto de condiciones influyó en la conformación de la federación y de sus procesos internos futuros. El segundo es la morfología, que permitió delinear la estructura organizativa y la posición de las integrantes, después estudiar la configuración de los vínculos externos y cómo influyen en dicha estructura. El tercero se centró en la dinámica, que alude a los procesos internos de participación, la manera cómo se involucran las integrantes en la toma de decisiones, funciones y actividades de la agrupación (véase Figura 2).

Para probar el modelo de análisis, debido a su larga trayectoria en el contexto estatal, la complejidad de su estructura interna y sus 
Figura 2. Modelo analítico para la sistematización de la trayectoria de la OS

\begin{tabular}{|c|c|c|}
\hline Niveles & Procesos & Variables \\
\hline \multirow{7}{*}{ Genealogía } & \multirow{7}{*}{$\begin{array}{l}\text { Gestación como } \\
\text { organización }\end{array}$} & Perfil de las fundadoras \\
\hline & & Contexto político, social y económico \\
\hline & & $\begin{array}{l}\text { Perfil de actores externos involucrados } \\
\text { en el proceso de gestación }\end{array}$ \\
\hline & & Participación en la toma de decisiones \\
\hline & & Movilidad en la estructura organizativa \\
\hline & & Trasmisión de conocimientos \\
\hline & & Flujos de información \\
\hline \multirow{3}{*}{ Morfología } & \multirow{3}{*}{$\begin{array}{l}\text { Constitución } \\
\text { de la estructura } \\
\text { organizativa }\end{array}$} & Estructura interna \\
\hline & & Perfil de los miembros activos \\
\hline & & Perfil de actores externos \\
\hline \multirow{5}{*}{ Dinámica } & \multirow{5}{*}{$\begin{array}{l}\text { Procesos de } \\
\text { participación }\end{array}$} & Proyectos y actividades de las integrantes \\
\hline & & Participación en la toma de decisiones \\
\hline & & Movilidad en la estructura organizativa \\
\hline & & Trasmisión de conocimientos \\
\hline & & Flujos de información \\
\hline
\end{tabular}

Fuente: elaboración propia, con base en Montes de Oca (2014); Alcántara (2011); Luna y Tirado (2005); Somuano (2011).

procesos de participación, se eligió a Cobanaras Federación Estatal de Sociedades de Solidaridad Social, formada por mujeres agrupadas en cinco sociedades de solidaridad social (SSS), ubicadas en municipios del sur de Sonora, que son: “Teresa Urrea”, en Cajeme; “Mayojusalit”, en Etchojoa; “Mujeres Cobanaras”, en Navojoa; “Esperanza Quirigueña”, en Quiriego y “Serranitas”, en Rosario Tesopaco (véase Figura 3). Para esta investigación sólo se consideraron las SSS activas en el periodo 2012-2015, y que se desempeñaban como cajas de ahorro, promotoras de derechos humanos y gestoras de proyectos para sus socias y la comunidad. 
Figura 3. Ubicación de las sociedades de Cobanaras Federación

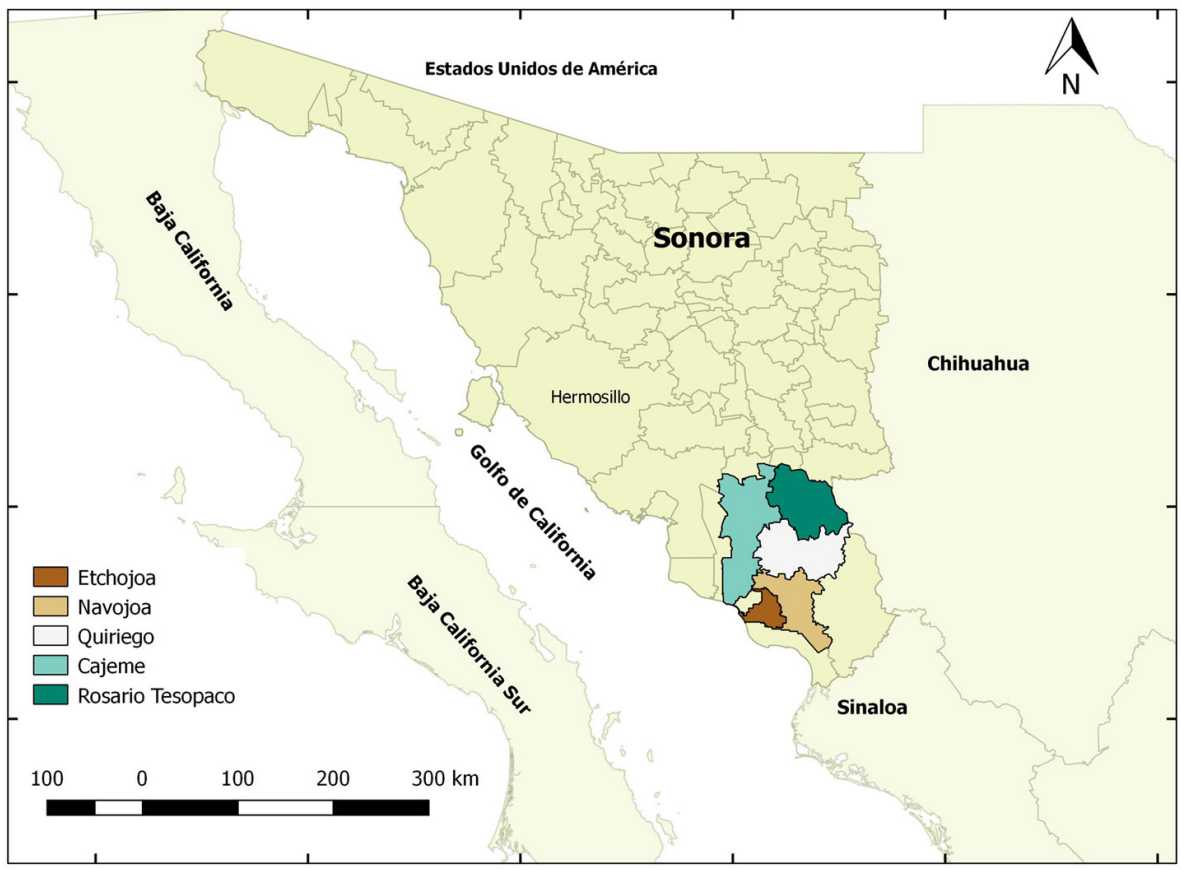

Fuente: elaboración propia, con datos de la Comisión Nacional para el Conocimiento y Uso de la Biodiversidad. http://www.conabio.gob.mx/informacion/gis/ (2012).

La información se recolectó en dos etapas; la primera fue de reconocimiento, en la que se hizo el primer contacto y recorrido a las sedes de cada SSS, para cumplir con dos objetivos: a) establecer el rapport con las informantes clave y las socias en general y b) generar los insumos para la reconstrucción de la genealogía, la morfología y la dinámica de Cobanaras Federación. Para ello se entrevistó a dos socias con cargo directivo y a dos de las fundadoras, además de cinco entrevistas colectivas a las integrantes de los comités directivos (presidenta, secretaria y tesorera) de cada SSS. A la par se revisaron tanto documentos publicados (libros, artículos) como internos (memorias, manuales o reportes elaborados por Cobanaras Federación), que perfilan el funcionamiento de la OS. 


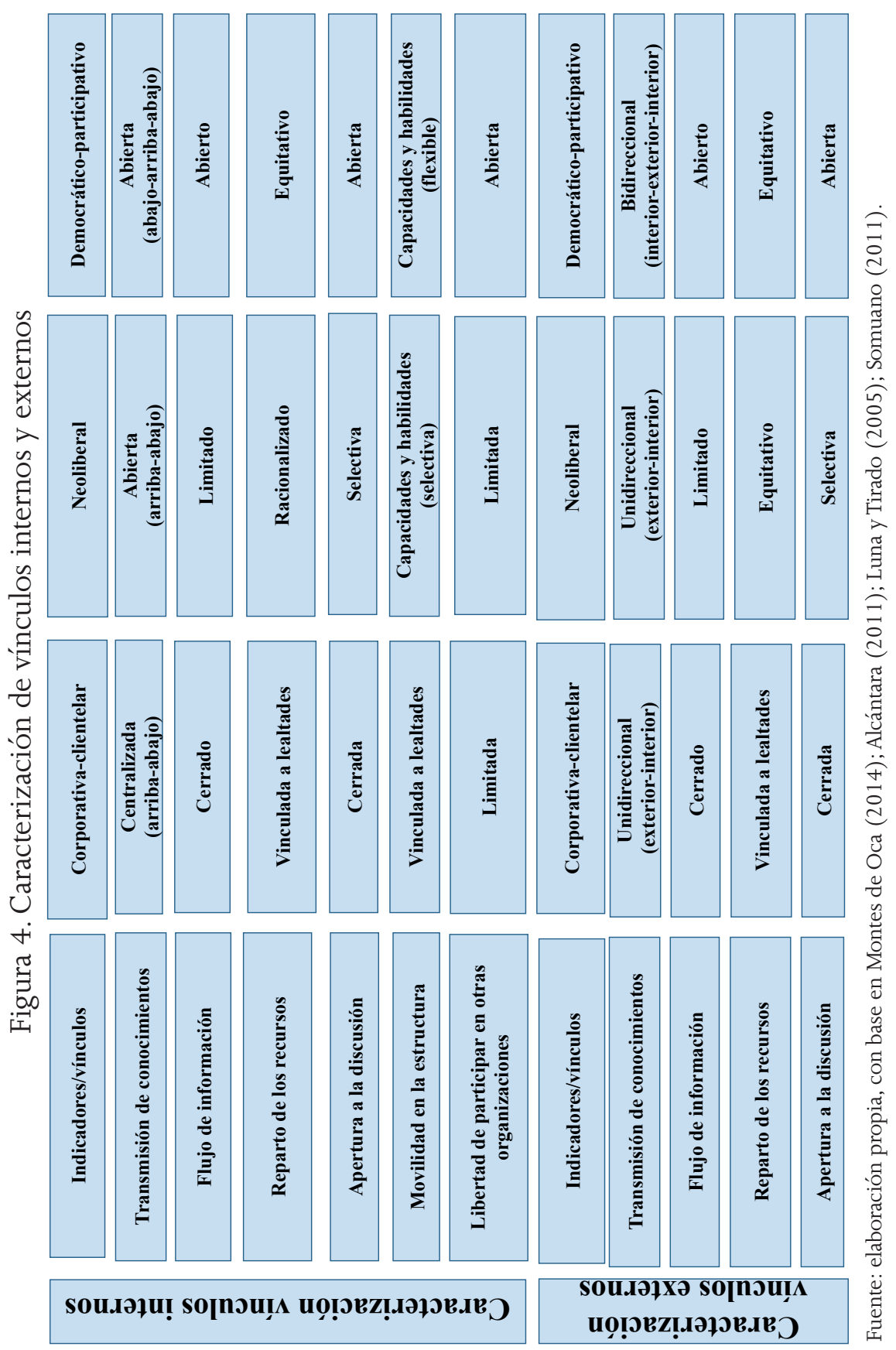


La finalidad de la segunda fue rescatar la cotidianidad y los procesos internos en que se generan los vínculos. Para ello se aplicaron cuestionarios y realizaron entrevistas a las socias en general, más la observación directa en los talleres convocados por Cobanaras Federación. El cuestionario se estructuró en tres bloques: a) perfil personal; b) perfil como socia y c) participación y opinión sobre las actividades y procesos internos. Se aplicó a 80 socias cuya edad mínima fue de 15 años y la máxima de 82; la media fue de 46.52. Asimismo, se participó en tres talleres a los que fueron convocadas las socias, a fin de conocer la forma en la que interactúan las asistentes, toman la palabra y discuten los temas.

Es importante destacar que el aporte de las fuentes en cada nivel de análisis fue distinto. Para la genealogía, la información provino de las fundadoras y de la revisión documental; para la morfología y la dinámica, además de las fuentes citadas, se consideró el discurso de las integrantes de los comités, más la información obtenida de cuestionarios y de entrevistas a socias en general, así como de la observación directa y participante que resultó imprescindible.

La información obtenida se procesó también en dos etapas, una de tipo descriptiva en la que se reconstruyó la gestación de la organización, su estructura formal y se identificaron los procesos de participación. En la segunda se caracterizaron los vínculos internos y externos de Cobanaras Federación (véase Figura 4), esto a partir del cruce de la tipología presentada en la Figura 1, con los indicadores de autonomía y democracia rastreables en los tres niveles del modelo analítico construido para este estudio.

\section{Análisis y caracterización de los vínculos de Cobanaras Federación}

Genealogía

El reparto de tierras de 1976 en el valle del Yaqui dejó fuera a gran cantidad de solicitantes, muchos pertenecientes al Frente Campesino Independiente, quienes continuaron su lucha como Frente Campe- 
sino Independiente Revolucionario (FCIR), fortalecidos por el brazo femenino del grupo 8 de Marzo, integrado por las mujeres que habían participado activamente en las invasiones de tierra, pero que no recibieron los beneficios del reparto agrario. Estas bases femeninas le dieron soporte a otro grupo que emergió del extinto Partido Revolucionario de los Trabajadores y del Grupo de Mujeres Autónomas, cuyas integrantes se adhirieron, como promotoras comunitarias, a la Fundación para el Desarrollo Comunitario y Apoyo Infantil ${ }^{1}$ (FUNDECAI), una ONG respaldada por Save the Children (fundadora/presidenta Cobanaras 2015). ${ }^{2}$

En 1978, la FUNDECAI estableció su centro de operación en Álamos, Sonora, con la puesta en marcha de un programa de desarrollo rural enfocado a la trasferencia de tecnologías limpias para las familias del municipio. Más tarde su estrategia viró hacia el trabajo con grupos de mujeres y hombres, en específico los pertenecientes al FCIR. El nuevo proyecto se desarrolló en torno a la simbiosis entre los recursos financieros y humanos de la FUNDECAI y a la experiencia de trabajo comunitario del FCIR en la región. El punto de partida se centró en la capacitación de las/os miembros como promotores de la cartera de proyectos de la FUNDECAI.

A las mujeres se les formó en primeros auxilios, saneamiento ambiental, nutrición y planificación familiar, surgió así la figura de las promotoras voluntarias de salud, quienes después se dedicaron a promover el ahorro y el préstamo, para establecer proyectos productivos. Sin embargo, estas actividades dependían de la colaboración entre la FUNDECAI y el FCIR, lo que significó en buena medida supeditarse a los proyectos colectivos mixtos del FCIR, y que las demandas femeninas quedaron rezagadas.

Si bien algunos líderes del FCIR reconocieron la aportación de las mujeres, las acciones cotidianas contradijeron el discurso, pues las mantuvieron al margen de los procesos de toma de decisiones, al de-

1 En la actualidad se denomina Fundación de Apoyo Infantil-Sonora (FAI-Sonora), que opera como institución de asistencia privada dedicada al desarrollo humano y comunitario, con enfoque sustentable, dirigido a población infantil, juvenil y adulta de comunidades yaqui y mayo (www.fai-son.org).

2 Cargo de la integrante de Cobanaras Federación, y año en que se realizó la entrevista. 
nostar sus opiniones en las asambleas. Así lo manifestó la presidenta de Cobanaras Federación, quien fuera una de las feministas adheridas al movimiento campesino: "Era común y cómo molestaban las frases como ¿la mamá de quién?, lanzadas por los compañeros cada vez que una de nosotras cuestionábamos sus decisiones o no concordábamos con sus opiniones" (presidenta Cobanaras 2014). De acuerdo con lo anterior, pese a que la irrupción de estas mujeres se dio en el contexto del Frente Campesino Independiente (Otero 1990) y su secuela el FCIR, eso no evitó que fueran víctimas de prácticas clientelar-corporativas, donde los varones centralizaban la toma de decisiones, obstaculizaban el flujo de información y conocimiento, vedaban los canales de discusión y condicionaban los recursos a lealtades.

Pese a esto, con la participación en el FCIR, las mujeres adquirieron experiencia política para la gestión de sus demandas y reconocimiento de sus derechos, lo que las impulsó a convocar, en 1986, al primer Encuentro regional de mujeres campesinas de Álamos (Encuentro de mujeres) como proyecto independiente. A la par, se desencadenaba un proceso de reconfiguración en la relación entre el FCIR, la FUNDECAI y las ahora organizadas bases femeninas, que inició con el distanciamiento y cese de colaboración con los primeros. La formación de la Unión Campesina de Álamos (UCA) ${ }^{3}$ absorbió las funciones de la FUNDECAI, hasta centralizar el flujo de información y el proceso de toma de decisiones en un grupo pequeño de líderes, en el que las bases femeninas quedaron sin representación efectiva.

En este escenario, ya versadas en la importancia de la organización y con vínculos nuevos, creados después de realizar tres encuentros de mujeres, en 1989 materializaron su proyecto al formar la Organización Regional de Mujeres de Álamos (ORMA). De acuerdo con una de sus fundadoras, las 520 socias se agruparon en torno a una estructura horizontal, "nos organizábamos por comités, más que una presidenta éramos encargadas y nos dividíamos las tareas" (fundadora/presidenta Cobanaras 2015).

Ante la retirada de la FUNDECAI y las prácticas de la UCA, al principio de la década de 1990, la encomienda principal de la ORMA

3 La UCA se formó por la FUNDECAI, a partir de la asignación de delegaciones en cada comunidad. La idea central era eliminar la intermediación entre las bases y la fundación. 
fue diversificar sus fuentes de financiamiento para administrar de manera autónoma los recursos obtenidos. Las alternativas fueron la Inter-American Foundation, agencia independiente del gobierno de Estados Unidos enfocada al desarrollo de sectores de escasos recursos de América Latina, y el Programa Mujeres en Solidaridad, impulsado por la Secretaría de Desarrollo Social. En 1991, ambos organismos proporcionaron recursos; la agencia para proyectos ganaderos, mejora de vivienda y trasporte, y el programa brindó apoyo financiero para crear un fondo "revolvente", y con ello la posibilidad de otorgar préstamos a los grupos de mujeres para que fueran administrados por la ORMA. A partir de ese momento se notó un viraje en los vínculos hacia un patrón neoliberal como estrategia para ganar autonomía, a través de la diversificación de recursos, a condición de involucrarse de lleno en el emprendimiento y la lógica empresarial.

Esta tendencia se fortalecería ante la necesidad creciente de inyectar recursos, lo que hizo más compleja la operación de la ORMA, sobre todo ante el imperativo de adoptar una figura jurídica que la avalara como organización. La opción más factible fue constituirse como SSS, porque esta figura permite tener acceso a financiamiento para el emprendimiento de proyectos productivos, tanto a fondo perdido como a crédito. El fin último de estas gestiones fue generar recursos propios, y depender menos de los externos. Así, en 1991 la ORMA se constituyó como la SSS Susana Sawyer, con la expectativa clara de generar vínculos con otros organismos de base femenina. A este llamado atendieron las SSS Jamutchim y Teresa Urrea, que a su vez compartieron su experiencia en la metodología de cajas de ahorro de la Financiera FINCA e incentivaron a la SSS Susana Sawyer para que la implementara, en 1992.

A menos de un año de iniciada la colaboración con FINCA, las tres OS resolvieron que las condiciones de operación eran poco convenientes, dado que el fondo "revolvente" formado a partir de los ahorros de sus socias, al igual que los intereses derivados de los préstamos eran administrados por dicha financiera. Por su parte, la SSS Susana Sawyer mantuvo funcionando los proyectos financiados por Inter-American Foundation, sin embargo el mal manejo de recursos por algunas de las socias responsables provocó que fracasaran; en parte, por la inercia de los proyectos a fondo perdido y la absorción de las deudas de las socias por el fondo "revolvente" común, práctica 
usual de la FUNDECAI, que tomó un rol asistencialista, típico de los vínculos de carácter clientelar-corporativo. En estas circunstancias, las SSS Jamutchim, Teresa Urrea y Susana Sawyer acordaron solicitar el financiamiento a la fundación estadounidense, y se les concedió, con la recomendación de agruparse como unión de sociedades. Así, en 1994 se constituyó Cobanaras ${ }^{4}$ Federación Estatal de Sociedades de Solidaridad.

Al analizar la conformación de Cobanaras Federación se evidencia el proceso de individualización del que fueron objeto algunas socias, detonado por la actitud excluyente del FCIR y de la UCA, y reforzado por las fundadoras feministas apoyadas por la FUNDECAI, en particular por su entonces directora. En este proceso subyace el rechazo y la ruptura del vínculo clientelar-corporativo con las organizaciones campesinas mixtas, en la búsqueda de autonomía y democracia, impulsada presumiblemente por los vínculos de democracia-participativa prevalecientes entre la membresía de la ORMA. Al final, la lucha por su subsistencia y la presión desde el exterior llevó a las socias a implicarse en una red de vínculos de tipo neoliberal, como estrategia para diversificar sus fuentes de financiamiento.

\section{Morfología}

La creación y regulación de las SSS compete a la Secretaría de Desarrollo Agrario, Territorial y Urbano (antes Secretaría de la Reforma Agraria), a través de La Ley de Sociedades de Solidaridad Social (Diario Oficial de la Federación, DOF 1976). En ella se establece que su dirección y administración deben estar a cargo de la Asamblea General o de la Asamblea General de Representantes, según el caso; el Comité Ejecutivo y otras instancias que dichas asambleas consideren necesarias para su funcionamiento.

Con base en lo anterior, Cobanaras Federación configuró una estructura interna que, a decir de su presidenta actual, permite una comunicación de doble vía federación-socias-federación y que, de

4 Cobanara proviene del vocablo yaqui-mayo kobanaaro que significa gobernador $y$, en este caso aplicado al sexo femenino, es gobernadora, del que deriva su lema Gobernando nuestro destino. 
Figura 5. Estructura operativa e instancias de toma de decisión

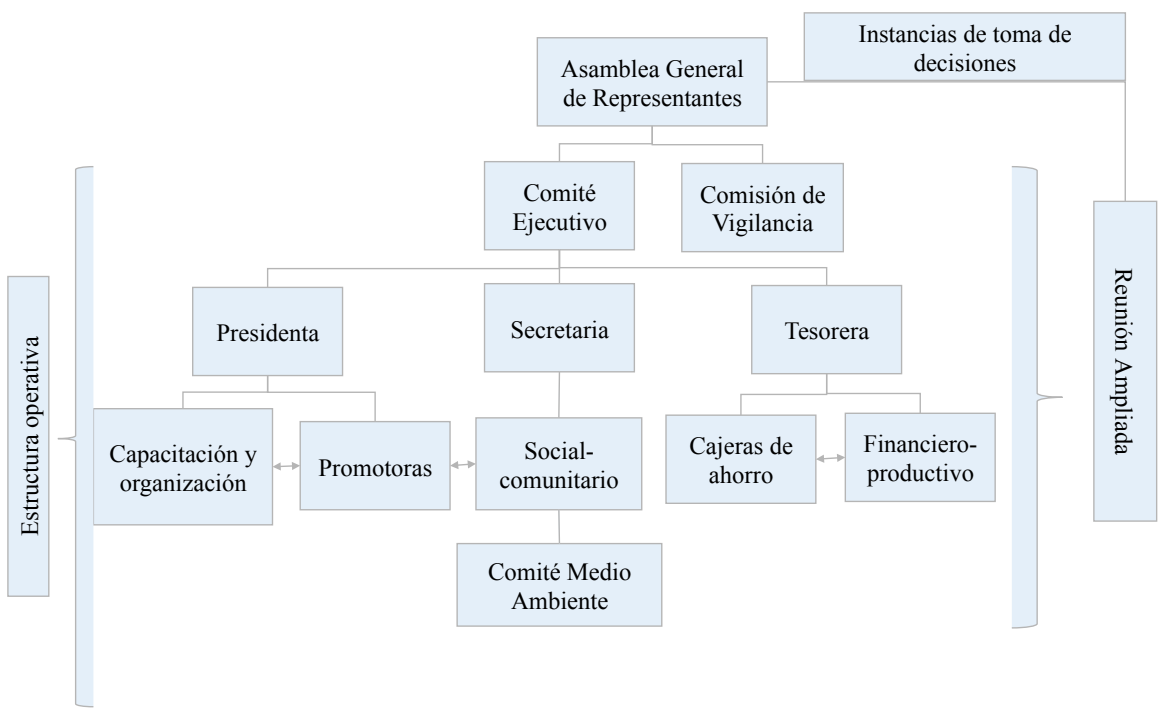

Fuente: adaptación a la propuesta por Del Pardo (2009), con base en las entrevistas a socias de Cobanaras Federación.

acuerdo con la sistematización de su morfología, consta de tres dimensiones: a) decisional, que integra las instancias de toma de decisiones; b) operativa, encargada de dar seguimiento y poner en marcha los acuerdos de la anterior y c) organizativa, referida a su estructura interna: federación-sociedad-grupo-socia (véase Figura 5).

A partir de este arreglo, la Asamblea General de Representantes es la autoridad máxima en la toma de decisiones, y está formada a razón de una representante de cada SSS por cada diez integrantes, y sesiona cada dos años. Una de las adecuaciones de Cobanaras con respecto a lo estipulado por la Ley de Sociedades de Solidaridad Social es la Reunión Ampliada de comités y la SSS, que sesiona cada cuatro meses, con la intención de mantener un flujo de información constante entre las bases y la federación, y promover la democracia-participativa entre las integrantes. 
La Reunión Ampliada está conformada por las socias de la estructura operativa, es decir, de la Comisión de Vigilancia; el Comité Ejecutivo y cada SSS; instancias dirigidas por una presidenta, una secretaria y una tesorera, con sus suplentes respectivas, y la red de promotoras comunitarias. Asimismo, incorpora a las encargadas de los programas que rigen las actividades de la federación. El papel de la Reunión Ampliada es muy importante en la toma de decisiones, además de discutir los avances y rumbos de acción para cada SSS, se realiza la selección de las posibles socias para la renovación de los comités.

En cuanto a su estructura como federación, la unidad operativa básica la constituyen los grupos de mujeres formados por 15 socias, en promedio, que a su vez integran las SSS. A lo largo de su trayectoria, Cobanaras Federación ha tenido un número fluctuante de SSS, con un máximo de once a finales de la década de 1990 y un mínimo de cinco, en la actualidad. Al igual que la federación, cada sociedad es dirigida y administrada por un comité ejecutivo (véase Figura 6).

Figura 6. Estructura organizativa de Cobanaras Federación (2014)

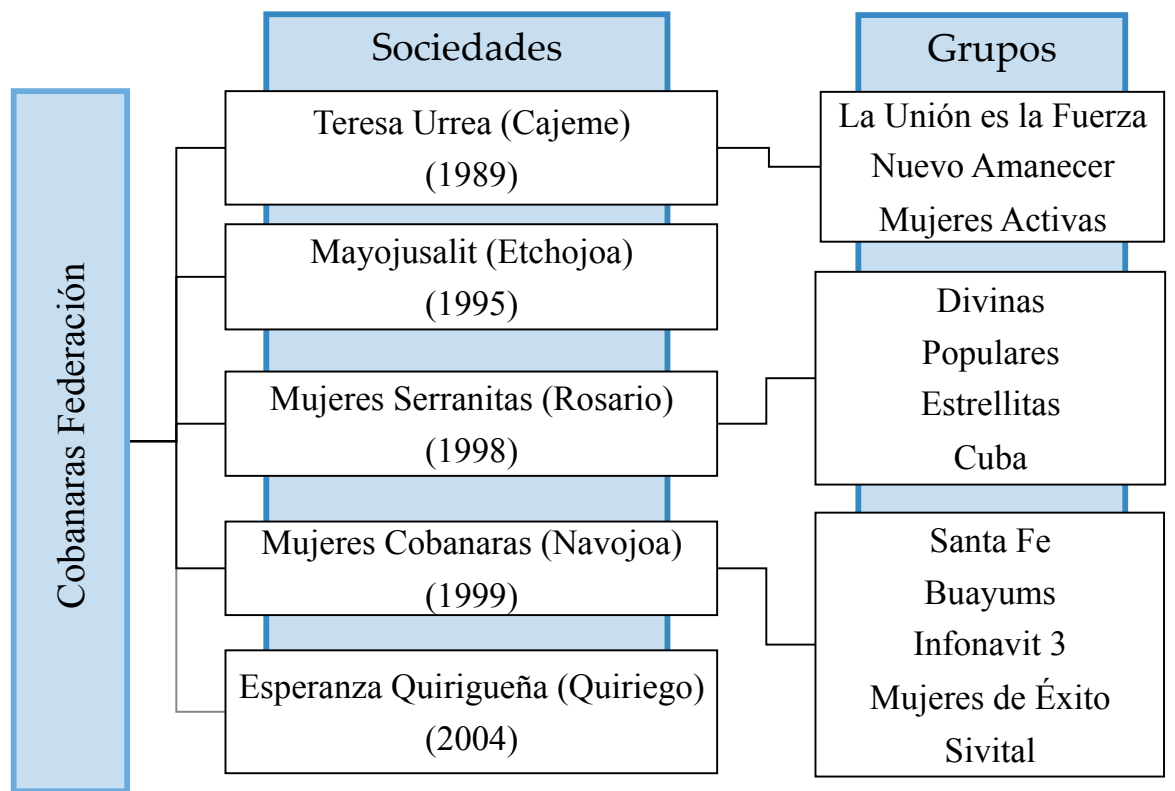

Fuente: elaboración propia, con base en Del Pardo (2009) y entrevistas al Comité Ejecutivo. 
Los vínculos con actores externos también se han ido modificando conforme a su trayectoria. Al igual que en su genealogía, se adhirieron a un organismo mixto, como la Unión Nacional de Organizaciones Regionales Campesinas Autónomas (UNORCA), que les brindó la oportunidad de interactuar con agrupaciones de base femenina de diversas entidades de México, y formar parte de la Asociación Mexicana de Mujeres Organizadas en Red, A. C. (AMMOR). Dentro de esta red, la proyección de Cobanaras Federación en el espacio público creció de manera paulatina, hasta formar parte del movimiento nacional de microfinanciamiento, que demandaba reglamentar jurídicamente la práctica del ahorro y el crédito popular.

A finales de los años noventa, el reconocimiento estatal creciente a Cobanaras Federación, impulsado por la UNORCA, sumado a la incorporación del principio de cuotas de género al Código Electoral para el Estado de Sonora, abrió senda para la participación política de algunas de sus socias. Primero con una diputación plurinominal en el Congreso local (1997-2000) y, en el siguiente trienio, la presidencia municipal de Benito Juárez, además de cargos en los cabildos de Álamos, Benito Juárez, Cajeme y Rosario Tesopaco.

A escala nacional, la coyuntura también se mostró favorable para sus aspiraciones de generar recursos propios. El sexenio de la alternancia política Partido Revolucionario Institucional-Partido Acción Nacional se caracterizó por reconocer el trabajo de la sociedad civil organizada, fomentar el emprendimiento empresarial e institucionalizar el financiamiento popular. Bajo estos lineamientos, Cobanaras Federación obtuvo, en 2002, el registro como Microfinanciera Cobanaras y un préstamo para su operación, a través del Programa Nacional de Financiamiento al Microempresariado. A partir de ese momento se les exigió promover y poner los préstamos a disposición de la población en general, esquema que requería la apertura de gerencias regionales en sus áreas de influencia: Rosario y Quiriego; Benito Juárez; Navojoa y Etchojoa, y la asignación de una encargada por cada región. Esta medida retiró a las promotoras del trabajo comunitario, para involucrarlas en actividades de crédito y cobranza.

Con base en lo anterior se puede afirmar que el patrón de vínculos neoliberal permeó en Cobanaras Federación, al hacer más compleja su estructura operativa y condicionar la pertenencia de las socias a los 
comités, a su profesionalización; también incidió en su despolitización, al reducir el vínculo con las bases a una mera transacción financiera. Una vez finalizado el convenio, en 2008, Cobanaras Federación comenzó su reestructuración con el propósito de reincorporar a las promotoras al trabajo comunitario, con el apoyo del Fondo Christensen. ${ }^{5}$

En marzo de 2009, en lo que se califica como un acto de ruptura contra el corporativismo y lucha por su democracia y autonomía, Cobanaras Federación deshizo su vínculo con la UNORCA, debido a la expulsión de la socia que fungía como titular del brazo femenino de unión. Una de las integrantes reflexionó sobre ello: "Para nosotras, salirnos de UNORCA fue un logro porque empezamos a subir nosotras nuestros proyectos, hacer muchas cosas más" (socia Cobanaras 2016). Pero también significó la escisión de la SSS Jamutchim, reconocida por ser una de las organizaciones fundadoras de Cobanaras que, atendiendo al principio de autonomía de las sociedades, en un primer momento refrendó su pertenencia tanto a la UNORCA como a Cobanaras Federación. Sin embargo, se fue desligando de las actividades de esta última, y se dio de baja tiempo después.

En 2010, tras la disolución de la mayoría de las SSS, adheridas en la década de 1990, la membresía de Cobanaras Federación se distribuyó en cinco de ellas, si se considera la separación de Mujeres Quirigueñas y la recién formada Esperanza Quirigueña, como escisión de la primera.

Entre 2010 y 2012, la membresía no presentó mayores cambios en lo que a la SSS se refiere, incluso viró, de una estrategia de expansión, hacia el fortalecimiento interno. En este proceso se destacan dos objetivos clave: a) el regreso a las bases, debido a la reconstrucción del vínculo con la SSS Susana Sawyer, y con él la posibilidad de retomar el viejo modelo organizativo, más apegado a la promoción comunitaria, con mayor participación de las socias en la toma de decisiones y b) la diversificación de fuentes de financiamiento que, entre otras, les llevó a crear la Red de Mujeres Organizadas en Sonora, como extensión

5 Es una fundación creada en 1957, con sede en San Francisco, California. En la actualidad brinda financiamiento a organizaciones de base, para el desarrollo de proyectos dirigidos a la preservación de la diversidad biocultural, con énfasis en el rescate de saberes indígenas (www.christensenfund.org). 
de Cobanaras Federación, bajo la figura de organización certificada como donataria autorizada. A través de ésta se pretende generar e inyectar recursos a Cobanaras Federación para lograr mayor control de su estructura y procesos; esto es, más autonomía en y entre todos los niveles organizativos: los grupos, las SSS y la federación.

En estos dos propósitos subyace el interés de brindar opciones de empleo remunerado a las socias, con la finalidad de retener e incorporar a mujeres jóvenes e incrementar la escolaridad del padrón, que en su mayoría es de primaria y secundaria. Por un lado, con ello se busca empoderar a la mujer, objetivo primordial de Cobanaras Federación, pero también asegurar su colaboración como profesionistas en sus SSS, y así atender los requerimientos de profesionalización cada vez mayores por parte de las instituciones y organizaciones canalizadoras de recursos.

El otro factor implícito en este planteamiento es la edad. De acuerdo con los cuestionarios aplicados a socias activas, el rango de edad fluctúa entre 33 y 60 años, con una media de 46, sin embargo la SSS Teresa Urrea tiene una media de 55 años, y su ritmo de afiliaciones es bajo respecto a las deserciones; esto se constató porque el padrón pasó de 87 a 39 mujeres en diez años. En principio, las socias explican esta disminución por la edad avanzada de la mayoría de las mujeres, que les impide participar, pero también por la falta de oportunidades para las jóvenes cuya incorporación plena se inhibe, ante la precariedad creciente de la situación económica, que las obliga a laborar jornadas dobles o a salir de su comunidad, y dejarles a las mayores la responsabilidad de la SSS. En virtud de lo anterior es que la prioridad de Cobanaras Federación es reforzar su capacidad para generar proyectos para las jóvenes.

En cuanto a las afiliaciones políticas, Cobanaras Federación y sus SSS se declaran apartidistas, reconocen la libertad completa de las socias para afiliarse o no a un partido, siempre que no realicen proselitismo en sus reuniones e instalaciones. Esta condición se cumple y es exigida por las socias, quienes durante las entrevistas se abstuvieron de externar cualquier comentario u opinión que pudiera relacionarse con alguna tendencia partidista. No obstante, mantienen una actitud positiva hacia el voto, lo consideran como una forma de expresión política a la que tienen derecho, y reprueban las posturas relacionadas con la corrupción. 
Las elecciones locales de 2015 constituyeron una prueba de su avance en autonomía y democracia internas; para la mayoría de las SSS, el proceso electoral no representó una amenaza para su vida organizativa, a pesar de la militancia activa de algunas de sus integrantes en distintos partidos y que fueron postuladas a puestos públicos. En contraste, la SSS Esperanza Quirigueña experimentó conflictos internos serios a raíz de diferencias partidistas, que derivaron en la disyunción de sus socias y la suspensión temporal de Cobanaras Federación.

Es importante destacar que lo expuesto no significó la disolución o separación definitiva de la SSS de Cobanaras Federación, por el contrario, al guardar distancia del conflicto, esta última apeló a los principios de autonomía y pluralidad, para que las mismas socias solucionaran su problemática, y a la vez se deslindaran de las prácticas que pudieran identificarlas como adherentes de algún partido político.

A la fecha, Cobanaras Federación continúa su trabajo con cinco SSS activas: Susana Sawyer, Teresa Urrea, Serranitas, Mayojusalit y Mujeres Cobanaras, además de la Microfinanciera Cobanaras y la Red de Mujeres Organizadas en Sonora. El objetivo de configurar así su estructura fue ampliar su campo de acción para generar recursos propios, y no depender de financiamiento externo, que condicione sus procesos internos a las reglas operativas de programas ajenos; pero también, para limitar prácticas clientelares y corporativas, que a través de la oferta de financiamiento pretendan regular la adhesión y conformación de las SSS, e impongan lineamientos que no concuerden con sus principios y proyecto integral basado en el ahorro, la promoción de derechos y el desarrollo de capacidades.

\section{Dinámica}

El artículo 2 de la Ley de Sociedades de Solidaridad Social estipula que entre los objetivos de las SSS está la creación de fuentes de empleo, la producción y la comercialización de bienes y servicios y, en general, el fomento de medidas que contribuyan a elevar el nivel de vida de los miembros de la comunidad (DOF 1976, 1). En ese tenor, Cobanaras Federación ha trabajado para posicionarse como una alternativa integral de empoderamiento para las mujeres. Nutrida de las experiencias 
generadas en la interacción con actores externos y con sus socias, resalta la búsqueda de la congruencia entre lo colectivo y lo individual, que va desde la independencia económica hasta la pugna por los derechos, y desde las demandas de solución a problemas inmediatos hasta su lucha feminista como agentes de cambio.

Las herramientas para concretar este proyecto son el ahorro y el desarrollo de capacidades. El primero, además de ser la condición para pertenecer a cualquiera de las SSS, la directiva de Cobanaras Federación lo ve que como "el gancho para organizar a las mujeres" (secretaria Cobanaras Federación 2013). Para las socias en general es la posibilidad de comprar sus cosas o de completar el gasto para que sus hijas/os sigan estudiando. Para algunas de ellas significa tener el poder de decisión que, combinado con el desarrollo de capacidades, es la base para el empoderamiento y la autonomía.

Esta formación les brinda la posibilidad de conocer otras maneras de concebir la vida y trasmitirla a sus hijos/as. La entonces tesorera (2012-2014) recordó que

nos íbamos varias, nos subíamos al camión con todo y chamaquero; por ejemplo, mi hijo, el menor es más atento y comprensivo, a diferencia del mayor, que casi no anduvo conmigo, que a veces hasta se molesta cuando salgo mucho; para nosotras, -como varias socias replican- conocer otros lugares, costumbres y cómo otras mujeres demandaban sus derechos, que muchas de nosotras aunque los conocíamos, no sabíamos cómo exigirlos.

Sin embargo, sólo algunas socias pueden asistir a todos los talleres, y acuden quienes la Reunión Ampliada considera que tienen potencial de liderazgo y capacidad para desempeñarse en algún comité, o tiempo para dedicarle a dicha tarea. Pese a que el modelo de formación de Cobanaras Federación, basado en la educación popular, contempla la réplica de las capacitaciones en cada una de las SSS por las asistentes, no siempre se lleva a cabo o no se trasmite en su totalidad.

Esto podría detonar un círculo vicioso, ya que son las integrantes de los comités, encargadas de los programas y promotoras, quienes por lo general tienen el acceso a los talleres y, por tanto, a acumular más capital humano y social. Por un lado, la discontinuidad en la tras- 
misión del conocimiento muestra que aún no se supera la retracción de las promotoras del trabajo comunitario a favor de las actividades de la microfinanciera. Por otro, puesto que el liderazgo es un conjunto de características que sitúa a las socias en el mapa de los comités -sin un consenso sobre sus descriptores-, a un grupo pequeño de mujeres le concierne designar quiénes cumplen con este perfil de liderazgo.

Desde la perspectiva de las integrantes del Comité Ejecutivo de Cobanaras Federación, la elección de la socias para capacitarse atiende a un criterio de recursos finitos, por lo que se tiene que invertir en quienes los catapulten y den continuidad a la organización. Pese a esta disposición, la mayoría de las mujeres consideró que todas tienen las mismas oportunidades de participar en algún comité, pero no es así cuando se refieren a ellas mismas. El estudio reveló que de las 80 entrevistadas, 53.8 por ciento respondió que no considera acceder a un cargo en los comités, aunque 48.8 reconoció que le gustaría formar parte de uno. Al preguntarles la razón por la cual no consideran participar en alguno, argumentaron falta de capacidad, de tiempo, su edad avanzada, tener hijas e hijos pequeños o que tenían trabajo fuera de casa. Al profundizar, la respuesta redundó en sus circunstancias personales como impedimento para asistir a los talleres, no obstante opinan que son importantes para ejercer las funciones propias de un cargo directivo.

Cabe mencionar que la complejidad creciente de la estructura y la diversificación de las fuentes de financiamiento, con criterios de operación específicos, hace que gran parte de la energía se centre en procesos administrativo-contables y rendición de cuentas hacia el exterior, lo que denota la presión neoliberal de los vínculos externos sobre los de tipo democrático-participativos, que se busca generar al interior. En mayor medida se apela a la profesionalización y especialización de las socias, a fin de cumplir en tiempo y forma con los trámites de la agenda de los organismos financiadores. Esta condición también demanda el despliegue de competencias y maximización de la ganancia que sitúa a las y los ciudadanos como individuos competidores en un juego de ganadores y perdedores, donde se compite por bienes públicos preestablecidos por profesionales y limitados por el presupuesto (Ochman 2006).

En esta ruta delineada por la eficiencia neoliberal, los recursos se racionalizan; la apertura a la discusión se vuelve selectiva, y la tras- 
ferencia de conocimientos es unidireccional. Es decir, ocurre en un esquema de arriba abajo, que poco considera las necesidades reales de la población. Por otro lado, desde el patrón clientelar-corporativo se busca la sumisión de las bases a un líder o a un grupo de ellos que concentran información, conocimientos y recursos financieros, que pueden repartir a cambio de lealtades.

La experiencia organizativa de Cobanaras Federación es un ejemplo de cómo las agrupaciones derivadas de los movimientos sociales, gestadas en la lucha por derechos, van navegando contracorriente resistiendo y adaptándose a los cambios políticos y económicos, que permean su estructura y dinámica, y tratan de imponer prácticas que distan de los arreglos generados por las bases que buscan reforzar los vínculos de la democracia-participativa.

\section{Conclusiones}

Al analizar la genealogía, la morfología y la dinámica de Cobanaras Federación se constató cómo su proyecto transitó, de los reclamos colectivos por la tierra y demandas por servicios públicos, hacia el fortalecimiento financiero, conquista de derechos y empoderamiento de la mujer. Esta transición refleja, por un lado, una tendencia hacia la profesionalización y especialización, coincidente con el modelo de sociedad civil promovido por los organismos internacionales y la despolitización e individuación características del modelo neoliberal. Y, por otro, facilitó la construcción de una conciencia de género que ha acercado a las mujeres a un desempeño más proactivo en el espacio público, y así las ha alejado de su antiguo papel de consumidoras pasivas de reglas e instituciones, característico del modelo clientelarcorporativo.

En términos generales, la continuidad de Cobanaras Federación por tres décadas en el espacio público ofrece evidencias de su consolidación como organización, único caso en Sonora. En gran medida, su permanencia se debe a la capacidad de sus líderes de capitalizar el contexto social, político y económico, así como de vincular lo social con lo político, primero al cortar su relación con el FCIR, en un momento en que las grandes estructuras gremiales perdían fuerza, y 
apoyarse en organizaciones internacionales que destinan gran parte de recursos a proyectos vinculados con el empoderamiento de la mujer y la equidad de género.

Aquí se observó cómo las grandes pasiones políticas e ideológicas de la lucha de clases, presentes en el FCIR y en el socialismo del Grupo de Mujeres Autónomas, difuminaban y expandían gradualmente su campo de acción hacia demandas universales por los derechos de las mujeres. Esto desde una tendencia hacia la actividad financiera y productiva, que exige la profesionalización constante para estar al tanto de la diversificación y competencia por recursos, así como de los esquemas de racionalización financiera que han moldeado su estructura y dinámica.

La dinámica de Cobanaras Federación está determinada por su estructura y, a su vez, por la complejidad de los contextos en los que se desarrollan sus vínculos, y se expresa en una tensión constante entre la presión neoliberal externa -de las instituciones financiadoras, privadas y gubernamentales- sobre las prácticas democráticas participativas internas. Así, a cuatro décadas de la implementación del modelo neoliberal y de la apertura a la organización autónoma, los requerimientos para el acceso a recursos financieros no parecen ser menos rígidos, sobre todo en la imposición de formas de organización desde arriba. En este sentido, es relevante regresar, como tanto se proclama desde el discurso oficial, hacia las bases para recuperar sus aciertos y tropiezos, para que guíen a la sociedad civil y a las instituciones públicas y privadas. La tipología de vínculos propuesta: clientelar-corporativo; neoliberal y democracia-participativa permitió capturar la complejidad de las interacciones imbricadas en las OS y en la manera de coexistir de los tres tipos de vínculos, y de reproducirse como formas de resistencia o adaptación, para sobrevivir en escenarios de transición en los que prevalecen tendencias sociopolíticas diversas y a veces contrapuestas.

\section{Agradecimientos}

Agradecemos la paciencia y generosidad de las mujeres de Cobanaras Federación por compartir su experiencia acumulada en estos años, 
dedicados a fomentar la organización y el empoderamiento de las mujeres sonorenses.

\section{Bibliografía}

Alcántara Nieves, Nehiby. 2011. Confianza y participación ciudadana en una organización migrante: el caso Centro Cultural y Artístico de Huachinera. Tesis de maestría en desarrollo regional, Centro de Investigación en Alimentación y Desarrollo, A. C.

Balibar, Étienne. 2012. Ciudadanía. Buenos Aires: Adriana Hidalgo Editora.

Barkin, David y Blanca Lemus. 2014. Rethinking the social and solidarity society in light of community practice. Sustentability 6: 64326445 .

Bartra Gross, Francisca. 1992. La mujer, nuevo sujeto social: un reto para la educación. Educación I (1): 95-106.

Beck, Ulrich. 2002. La sociedad del riesgo global. Madrid: Siglo XXI.

Beck, Ulrich. 1997. La reinvención de la política: hacia una teoría de la modernización reflexiva. En La modernidad reflexiva:políica, tradición y estética en el orden social moderno, coordinado por Ulrich Beck, Anthony Giddens y Scott Lash, 13-74. Madrid: Alianza.

BID/PNUD. 1993. Reforma social y pobreza. Hacia una agenda integral de desarrollo. Trabajos del Foro sobre reforma social y pobreza. Washington: BID/PNUD.

Buvinic, Mayra y Vivian Roza. 2004. La mujer, la política y el futuro democrático de América Latina. Washington: BID.

Calderón Gutiérrez, Fernando. 2012. América Latina y el Caribe: tiempos de cambio. Nuevas consideraciones sociológicas sobre la democracia y el desarrollo. 
Buenos Aires: Teseo; Facultad Latinoamericana de Ciencias Sociales (FLACSO).

Calderón Gutiérrez, Fernando. 2011. Movimientos culturales y la emergencia de una nueva politicidad. Política e Sociedade 10 (18): 75 95.

Canabal Cristiani, Beatriz. 2003. Mujeres indígenas y democracia. Una primera reflexión desde la montaña de Guerrero. La Ventana (18): 210-253.

Cohen, Jean y Andrew Arato. 2000. Sociedad civil y teoría política. México: Fondo de Cultura Económica (FCE).

Coraggio, José Luis. 2008. Crítica de la política social neoliberal: las nuevas tendencias. En Es posible pensar una nueva política social para América Latina, compilado por Juan Ponce Jarín, 81-94. Ecuador: FLACSO.

Dagnino, Evangelina, José Alberto Olvera y Aldo Panfichi. 2006. Para otra lectura de la disputa por la construcción democrática en América Latina. Colección Cuadernos para la Democratización. México: Centro de Investigaciones y Estudios Superiores.

Del Pardo, Roberto. 2009. Cobanaras. Gobernando nuestro destino. Hermosillo: Cobanaras, AMMOR; Christensen Found; Instituto Sonorense de la Mujer.

Diamond, Larry. 1997. Repensar la sociedad civil. Revista Metapolíica 1 (2):183-198.

DOF. I 976. Ley de Sociedades de Solidaridad Social. Cámara de Diputados del H. Congreso de la Unión, México.

Durand Ponte, Víctor Manuel. 2002. El imperio de la desconfianza: debilidad mexicana. Acta Sociológica (36): 85-121.

Echavarría, Corina y Gabriela Bard. 2013. Frente a la crisis neoliberal, las mujeres se organizan: la experiencia de participación comuni- 
taria de las mujeres de sectores populares en la Argentina. Nomadías (17): 89-107.

Esteva, Gustavo. 2014. Commoning in the new society. Community Development Journal 49 (S1): 144-159.

Garretón Merino, Manuel Antonio. 2006. Sociedad civil y ciudadanía en la problemática latinoamericana actual. En Ciudadanía, sociedad civil y participación política, compilado por Isidoro Cheresky, 145-159. Buenos Aires: Miño y Dávila.

Garretón Merino, Manuel Antonio. 2002. La transformación de la acción colectiva en América Latina. Revista de la CEPAL (76): 7-24.

Harvey, David. 2007. Breve historia del neoliberalismo. Madrid: Ediciones Akal.

Isin, Egin. 2009. Citizenship in flux: the figure of the activist citizen. Subjectivity 29: 367-388.

Isin, Engin y Bryan Turner. 2002. Introduction. En Handbook of citizenship studies, editado por Engin F. Isin y Bryan S. Turner Bryan, 1-10. Londres: Sage.

Jenkins, Katy. 2011. Depoliticisation and the changing trajectories of grassroots women's leadership in Peru: from empowerment to service delivery? Latin American Studies 43 (2): 299-326.

Lara Flores, Sara María. 1994. Las mujeres: ¿nuevos actores sociales en el campo? Revista Mexicana de Sociología 56 (2): 77-88.

Lechner, Norbert. 2004. Los desafíos políticos del cambio cultural. Revista Educación 314: 39-51.

Levitsky, Steven y Leandro Wolfson. 2004. Del sindicalismo al clientelismo: la transformación de los vínculos partido-sindicatos en el peronismo, 1983-1999. Desarrollo Económico 44 (173): 3-32. 
Luna, Matilde y Ricardo Tirado. 2005. Modos de toma de decisiones en las asociaciones y desempeño político. Revistas de Ciencias Políticas y Sociales XLVII (153): 57-74.

Martínez, Luz, Emma Zapata, Pilar Alberti y Rufino Díaz. 2005. Género y poder en tres organizaciones rurales de la región lagunera. Revista Mexicana de Sociología 67 (2): 271-319.

Montes de Oca, Laura Beatriz. 2014. ¿Innovaciones democráticas? Análisis del Consejo Consultivo de Telecomunicaciones en México. Revista Mexicana de Sociología 76 (2): 287-320.

Ochman, Marta. 2006. La reconfiguración de la ciudadanía:los retos del globalismo y de la posmodernidad. México: Miguel Ángel Porrúa, Instituto Tecnológico y de Estudios Superiores de Monterrey, campus Estado de México.

Olvera Rivera, José Alberto. 2000. Organizaciones de la sociedad civil: breve marco teórico. Documentos de Discusión sobre el Tercer Sector (8): 4-20.

Ortiz Gómez, María Guadalupe. 2014. El perfil del ciudadano neoliberal: la ciudadanía de la autogestión neoliberal. Sociológica 29 (83): 165-200.

Otero, Gerardo. 1990. El nuevo movimiento agrario: autogestión y producción democrática. Revista Mexicana de Sociología 52 (2): 93-124.

Prats Catalá, Joan. 2005. Modos de gobernación de las sociedades globales. En La gobernanza hoy: 10 textos de referencia, coordinado y traducido por Agustín Cerrillo, 145-172. Madrid: Instituto Nacional de Administración Pública.

Sánchez Salcedo, José Fernando. 2008. Reflexiones sobre el poder de los vínculos en la sociedad colombiana. Nóesis. Revista de Ciencias Sociales y Humanidades 17 (34): 204-234. 
Somuano, María Fernanda. 2011. Sociedad civil organizada y democracia en México. México: El Colegio de México.

Touraine, Alain. 2007. El mundo de las mujeres. España: Paidós Ibérica.

Touraine, Alain. 2006. Los movimientos sociales. Revista Colombiana de Sociología (27): 255-278.

Touraine, Alain. 2001. ¿Podemos vivir juntos? Iguales y diferentes. México: FCE.

Touraine, Alain. 2000. ¿Qué es la democracia? México: FCE.

Wieviorka, Michel. 2011. Una sociología para el siglo XXI. Barcelona: Editorial UOC. 